\title{
Composition of Lipopolysaccharides from Four Strains of Erwinia amylovora
}

\author{
By T. C. RAY, ${ }^{\dagger} \dagger$ A. R. W. SMITH, ${ }^{*}$ K. J. CARTER ${ }^{2}$ AND \\ R. C. HIGNETT ${ }^{2}$ \\ ${ }^{1}$ School of Biological Sciences and Environmental Health, Thames Polytechnic, Wellington Street, \\ London SE18 6PF, UK \\ ${ }^{2}$ East Malling Research Station, East Malling, Maidstone, Kent ME19 6BJ, UK
}

(Received 12 February 1986; revised 12 May 1986)

The lipopolysaccharides (LPSs) from four isolates of Erwinia amylovora were examined. One isolate was virulent and capsulate, and it produced extracellular polysaccharide (EPS). Three were avirulent, of which one was capsulate and produced EPS; the remainder were noncapsulate and did not produce EPS. LPS was recovered from the cells and from the culture medium. Material extracted from the cells using phenol-water was indistinguishable from LPS extracted with phenol-chloroform-light petroleum. Acid hydrolysis released lipid A which contained in all cases glucosamine, phosphate and the fatty acids 12:0, 14:0 and 3-OH 14:0. The carbohydrate released by mild acid hydrolysis was resolved by gel permeation chromatography into three components: I, a partially included species identified as core substituted with a short sidechain of fucose, galactose and glucose; II, an unsubstituted core oligosaccharide containing heptose, glucose, uronic acid, amino compounds and 3-deoxy-2octulosonic acid (KDO); III; a totally-included low $M_{\mathrm{r}}$ fraction containing KDO, phosphate and amino compounds. The sidechain component was missing from LPS of one of the noncapsulate strains that did not produce EPS. This strain is believed to lack UDP-glucose-4epimerase, a key enzyme in the biosynthesis of galactose. Galactose (with glucose and uronic acid) is known also to be a component of EPS. Defects in galactose synthesis may therefore affect the assembly of LPS as well as EPS.

\section{INTRODUCTION}

Erwinia amylovora is the causal agent of fireblight disease of pome trees. Although the mechanism by which the disease is established and progresses is not known, all virulent strains are capsulate and produce an extracellular polysaccharide (EPS) which has the same chemical composition whether produced in the plant host or in artificial culture media containing sorbitol (Bennett \& Billing, 1980; Ayers et al., 1979; Slade \& Tiffin, 1978). Goodman et al. (1974) suggested that EPS was a host-specific wilting toxin, a view which is now questioned (Beer et al., 1983; Van-Alfen \& McMillan, 1982). Bennett \& Billing (1980) established that EPS contained galactose with lesser amounts of glucose, uronic acid and mannose, but its structure has never been satisfactorily described (see Goodman, 1983). Bennett (1980) isolated an avirulent capsulate strain (P66), thus establishing that EPS could not be the sole determinant of virulence.

Romeiro et al. $(1981 a)$ isolated an agglutinin from apple seeds capable of precipitating EPS, but which agglutinated avirulent strains more efficiently than virulent ones. Romeiro et al.

+ Present address: Department of Plant Biology, University of Birmingham, PO Box 363, Birmingham B15 2TT, UK.

Abbreviations: EPS, extracellular polysaccharide; KDO, 3-deoxy-2-octulosonic acid; PCP, phenol-chloroformlight petroleum; PW, phenol-water; TEB, triethylamine/EDTA buffer; YPA, yeast peptone agar. 
$(1981 b)$ considered lipopolysaccharide (LPS) as a possible receptor for the agglutinin and found that isolated LPS from the avirulent strain E8 was precipitated by the agglutinin.

Previous reports (Chatterjee et al., 1977; Romeiro et al., 1981 b) on the chemical composition of LPS from E. amylovora were brief and made no reference to the possible contamination of LPS extracts with capsular or extracellular polysaccharides.

In this report, we describe the composition of purified LPS from four strains of E. amylovora.

\section{METHODS}

Organisms. Four strains of E. amylovora were provided by Dr E. Billing (East Malling Research Station): strain $T$, a capsulate, wild-type virulent isolate that produces EPS; strain S, a non-capsulate, avirulent mutant of strain $T$ that does not produce EPS and is resistant to phage 4S; strain P66, a capsulate, avirulent strain that produces EPS and is believed to act synergistically with strain $\mathrm{S}$ to produce disease symptoms (Bennett \& Billing, 1978; Bennett, 1980); and strain E8, the non-capsulate, avirulent strain that does not produce EPS that was used by Romeiro et al. $(1981 a, b)$ and was originally provided by Dr R. N. Goodman (University of Missouri).

Bacteria were maintained on yeast peptone agar (YPA) by monthly serial subculture, and as lyophilizates. Chemicals and authentic standards. Pronase (B grade), was from Calbiochem-Behring; ribonuclease $1(4 \times$ recrystallized; from bovine pancreas) was from $\mathrm{BDH}$; ammonium 3-deoxy-2-octulosonate (KDO), Dmannoheptulose and methyl nonadecanoate were from Sigma ; 3-hydroxybiphenyl was from Eastman Kodak, and authentic bacterial fatty acid methyl ester mixture was from Supelco.

Batch culture of bacteria and extraction of LPS. The asparagine-sorbitol-minimal salts medium of Bennett \& Billing (1980) was modified for bulk culture of the bacteria to contain $\left(1^{-1}\right)$ : sorbitol, $20 \mathrm{~g}$; asparagine, $4 \mathrm{~g}$; $\mathrm{K}_{2} \mathrm{HPO}_{4}, 2 \mathrm{~g} ; \mathrm{MgSO}_{4} .7 \mathrm{H}_{2} \mathrm{O}, 0.2 \mathrm{~g}$; nicotinic acid, $0.2 \mathrm{~g}$; thiamin. $\mathrm{HCl}, 0.2 \mathrm{~g}$; trace elements (Bauchop \& Elsden, 1960), $1 \mathrm{ml}$; pH 6.8-7.0. Bacteria were grown in 81 batch culture using a model 1/1000 fermenter (L H Engineering) fitted with a 101 baffled vessel. Temperature was maintained at $26^{\circ} \mathrm{C}$, and $\mathrm{pH}$ at 7.0 (by automatic addition of $2.5 \mathrm{M}-\mathrm{HCl}$ ). Aeration was provided (3-4l air $\mathrm{min}^{-1}$ ) with agitation at 900 r.p.m. Polyethylene glycol antifoam (PPG 2000; Shell), $2 \mathrm{ml}$, was added at the start of culture. Cultures were inoculated with a 11 starter grown in shake flasks for $24 \mathrm{~h}$ in the same medium, and after 21-24 h bacteria were harvested, washed twice with distilled water and dried by acetone treatment (Quirk et al., 1976) to yield $1-2 \mathrm{~g}$ dried cells ( 1 of culture) ${ }^{-1}$. Cultural purity was confirmed by plating on YPA and bacteria were checked for their ability to produce characteristic growth on pear slices (Billing, 1984).

LPS was extracted from the dried cells by sequential treatment with phenol-chloroform-light petroleum (b.p. 40-60 ${ }^{\circ} \mathrm{C}$ ) (PCP; Galanos et al., 1969) and hot aqueous phenol (PW; Westphal \& Jann, 1965). Culture supernatants were concentrated 10 -fold by rotary evaporation and dialysed against distilled water. LPS was then recovered by centrifugation at $100,000 \mathrm{~g}$ for $2.5 \mathrm{~h}$. LPS from all sources was purified by repeated centrifugation at $100000 \mathrm{~g}$ for $2.5 \mathrm{~h}$ after successive treatment with ribonuclease $\left(0.1 \mathrm{mg} \mathrm{m}^{-1}\right)$ for $16 \mathrm{~h}$ at $4{ }^{\circ} \mathrm{C}$, and Pronase $(0.1 \mathrm{mg}$ $\mathrm{ml}^{-1}$ ) for $2 \mathrm{~h}$ at $37^{\circ} \mathrm{C}, \mathrm{pH} \mathrm{7.0,} \mathrm{in} \mathrm{sodium} \mathrm{phosphate} \mathrm{buffer.} \mathrm{The} \mathrm{purified} \mathrm{LPS} \mathrm{was} \mathrm{stored} \mathrm{in} \mathrm{solution} \mathrm{over}$ chloroform at $4^{\circ} \mathrm{C}$.

Assessment of purity of LPS extracts. Purified LPS was subjected to the following procedures designed to separate any contaminating polysaccharides present. (1) Disaggregation in triethylamine/EDTA buffer (Carlson et al., 1978). Lyophilised LPS (10-20 mg) was dissolved in $100 \mathrm{~mm}$-triethylamine/300 mM-EDTA buffer, pH 7.0 (TEB), and dialysed against 10-fold-diluted TEB for $48 \mathrm{~h}$. The sample was then passed down a column $(3.2 \times$ $42 \mathrm{~cm}$ ) of Sepharose 4B equilibrated with the same buffer. Fractions were assayed for carbohydrate and KDO. (2) Alkaline de- $O$-acylation. LPS (5-10 mg) was de- $O$-acylated in alkali as described by Chester \& Meadow (1975) and chromatographed on a column $(1.5 \times 39 \mathrm{~cm})$ of Sephadex G-200 (superfine). Fractions ( $3 \mathrm{ml})$ were analysed for carbohydrate and KDO.

Acid hydrolysis of LPS. The sidechain and core components were released from lipid A by hydrolysis of LPS (3$200 \mathrm{mg}$ ) with $1 \%(\mathrm{v} / \mathrm{v})$ acetic acid at $100^{\circ} \mathrm{C}$ for $90 \mathrm{~min}$ (Lüderitz et al., 1965). Lipid A was extracted with two portions of diethyl ether and any remaining insoluble material was removed by low speed centrifugation. Sidechain and core components in the aqueous residue were separated on a column of Sephadex G50 $(3.5 \times$ $40 \mathrm{~cm}$ ), eluted with $0.05 \mathrm{M}$-pyridine/acetic acid buffer, pH 5.4. Fractions $(15 \mathrm{ml})$ were collected and assayed for carbohydrate and phosphate. Monosaccharides were released from whole LPS by heating LPS with $2.5 \mathrm{M}-\mathrm{HCl}$ for $20 \mathrm{~min}$ at $100^{\circ} \mathrm{C}$ (Smith et al., 1985). This procedure resulted in the release of all the monosaccharides with the partial loss of some, especially fucose (see Results), for which correction was made by submitting samples of authentic monosaccharides to identical treatment and measuring the quantities remaining. Monosaccharides and amino compounds were released from the core by using either $2.5 \mathrm{M}-\mathrm{HCl}$ for $20 \mathrm{~min}$ at $100{ }^{\circ} \mathrm{C}$ or $0.5 \mathrm{M}-\mathrm{H}_{2} \mathrm{SO}_{4}$ for $4 \mathrm{~h}$ at $100^{\circ} \mathrm{C}$ in ampoules sealed under $\mathrm{N}_{2}$. Monosaccharides were released from the sidechain by using $0.5 \mathrm{M}-$ $\mathrm{H}_{2} \mathrm{SO}_{4}$ under identical conditions to those described for hydrolysis of the core.

Methanolysis of LPS and analysis of fatty acid methyl esters. Fatty acids, released from LPS by methanolysis, were analysed as their methyl esters by the GLC methods described by Smith et al. (1985). 
For MS, separations were done in a Pye model 104 gas chromatograph equipped with a column $(4 \mathrm{~mm} \times$ $152 \mathrm{~cm}$ ) of $3 \% \mathrm{SP} 2100-\mathrm{DOH}$ on Supelcoport, operated with temperature programming from $90-190{ }^{\circ} \mathrm{C}$ at $1{ }^{\circ} \mathrm{C}$ at

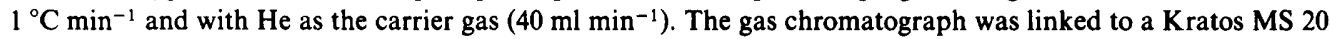
mass spectrometer interfaced with a VG 2015 data system. The membrane evaporator was kept at $175^{\circ} \mathrm{C}$; the ion source temperature was $200^{\circ} \mathrm{C}$ and the ionization potential $70 \mathrm{eV}$.

Analysis of neutral sugars released by acid hydrolysis. Alditol acetate derivatives of neutral sugars were prepared as described by Albersheim et al. (1967), and analysed on a packed column $(3.2 \mathrm{~mm} \times 188 \mathrm{~cm})$ of $3 \%$ SP2340 on $100 / 120$ mesh Supelcoport with temperature programming from $145-200{ }^{\circ} \mathrm{C}$ at $1{ }^{\circ} \mathrm{C} \mathrm{min}-1$ and with $\mathrm{N}_{2}$ as the carrier gas $\left(20 \mathrm{ml} \mathrm{min}^{-1}\right)$; they were quantified by integration of the peak areas, using myo-inositol as the internal standard.

Chemical estimations. The methods used for the determination of amino compounds, and of nucleic acid and LPS components, were described by Smith et al. (1985). In addition, uronic acid was determined on intact and hydrolysed LPS by the 3-hydroxybiphenyl method (Blumenkrantz \& Asboe-Hansen, 1973) with D-glucuronic acid as the standard.

\section{RESULTS}

\section{Extraction and purity of LPS}

In asparagine-salts medium containing $20 \mathrm{~g}$ sorbitol $\mathrm{1}^{-1}$, the production of EPS by $E$. amylovora strains T, P66 and E8 at late exponential phase of growth was largely suppressed. LPS could be extracted from cells of all four strains by sequential PCP-PW extraction and was also found in culture supernatants. Comparisons were made of the quantities of KDO-containing material recovered from the three sources. Isolate $\mathrm{T}$ yielded [ $\mathrm{g}$ dry wt cells $\left.)^{-1}\right]$, by PCP extraction, $101 \mu \mathrm{g} \mathrm{KDO}$; by PW extraction, $162 \mu \mathrm{g}$; and from the culture supernatant, $297 \mu \mathrm{g}$. Cultures of strains P66 and E8 gave similar yields, but the corresponding values for the cultures of strain S were 452,92 and $54 \mu \mathrm{g} \mathrm{KDO} \mathrm{(g} \mathrm{dry} \mathrm{wt} \mathrm{cells)}{ }^{-1}$.

After treatment with ribonuclease and Pronase, LPS was free from nucleic acid and peptidoglycan (see below) and contained approximately $1-2 \%(w / v)$ protein by Folin's assay. LPS samples from strains $T$ and $S$ were used to determine whether LPS extracts contained polysaccharide components that lacked KDO. The results of these experiments are given below.

\section{Disaggregation of LPS from strain T}

Native LPS eluted from Sepharose 4B at the void volume of the column and therefore had an apparent $M_{\mathrm{r}}$ in excess of $5 \times 10^{6}$, which indicated a high degree of molecular aggregation. A reduction in the degree of aggregation was obtained by treatment with TEB to remove divalent cations. LPS was then found to be included on a column of Sepharose 4B (Fig. 1). The disaggregation process was apparently not immediate. Thus, LPS treated in TEB for only $3 \mathrm{~h}$ before chromatography gave a broad elution profile on Sepharose $4 B$, indicating a wide size range of LPS aggregates, but LPS treated for $3 \mathrm{~h}$ followed by dialysis for $48 \mathrm{~h}$, as described above, eluted as a single, narrower symmetrical peak, indicating that LPS had disaggregated more completely. However no separate carbohydrate peaks lacking KDO were detected.

\section{De-O-acylation}

Chromatography on Sephadex G-200 of deacylated LPS from strain T yielded three peaks containing both carbohydrate and KDO (Fig. 2). After a second treatment with alkali, the material of higher $M_{\mathrm{r}}$ (peak A) emerged in an identical position, indicating that deacylation was probably complete after the first treatment. Chromatography of the deacylated LPS from strain S on Sephadex G200 yielded a single broad, included peak containing carbohydrate and KDO. Neither LPS from strain $\mathrm{T}$ nor from strain $\mathrm{S}$ yielded any separate carbohydrate peaks lacking KDO.

\section{Analysis of whole LPS}

The overall composition of LPS from the four $E$. amylovora strains is given in Table 1. Hydrolysis of LPS in $2.5 \mathrm{M}-\mathrm{HCl}$ at $100^{\circ} \mathrm{C}$ for $20 \mathrm{~min}$ quantitatively released lipid $\mathrm{A}$, which amounted to $20-25 \%$ of the dry weight of the original LPS. Analysis of the aqueous residue indicated that $\mathrm{KDO}$, heptose, glucose and uronic acid were present in approximately similar 


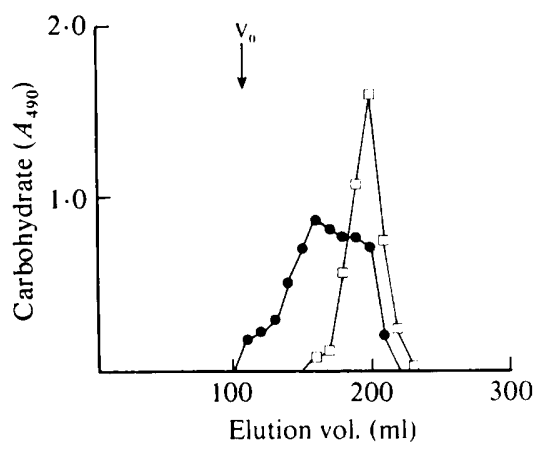

Fig. 1. Elution profile on Sepharose 4B of LPS from $E$. amylovora strain T after treatment with TEB. Lyophilized LPS $(10 \mathrm{mg})$ was dissolved in TEB and kept for $3 \mathrm{~h}$ at room temperature, then either passed down a column $(3.2 \times 42 \mathrm{~cm})$ of Sepharose 4 B equilibrated against TEB diluted 10-fold with water $(O)$, or dialysed for $48 \mathrm{~h}$ against diluted TEB prior to column chromatography ( $\square$ ). Samples (1 ml) were analysed for total carbohydrate. Arrow indicates void volume $\left(\mathrm{V}_{0}\right)$.

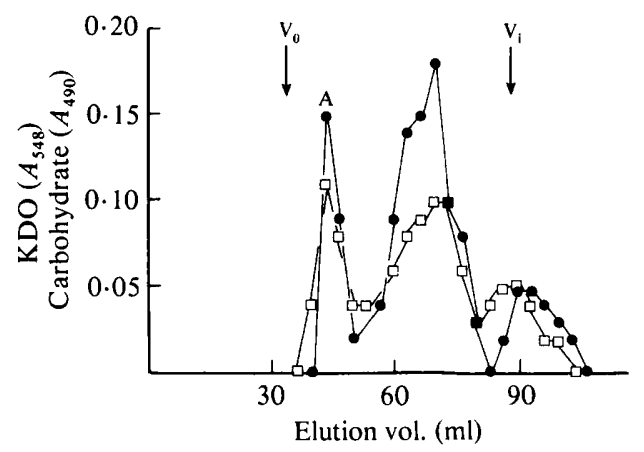

Fig. 2. Fractionation on Sephadex G-200 of de- $O$-acylated LPS from $E$. amylovora strain T. LPS ( $7 \mathrm{mg}$ ) was de- $O$-acylated in ethanolic $0 \cdot 1 \mathrm{M}-\mathrm{NaOH}$, and the water-soluble residue was eluted from a column $(1.5 \times 39 \mathrm{~cm})$ of Sephadex G-200 equilibrated against $50 \mathrm{~mm}$-pyridine/acetic acid buffer, pH 5.4. Fractions were assayed for total carbohydrate $(0 ; 0.5 \mathrm{ml}$ portions) and for $\mathrm{KDO}(\square ; 1 \mathrm{ml}$ portions). Arrows indicate void $\left(\mathrm{V}_{0}\right)$ and totally included $\left(\mathrm{V}_{\mathrm{i}}\right)$ volumes. A, high $M_{\mathrm{r}}$ peak (see text).

amounts in each LPS. Phosphorus was present in varying amounts, and strain S appeared to contain less amino sugar and less total amino compounds than did LPS from the other three strains. Analysis of the neutral sugars by GC of alditol acetates showed galactose and fucose to be present in LPS from strains T, P66 and E8, but not in LPS from strain S. Significant amounts of calcium were present in each LPS.

Glucosamine was present in the $6.1 \mathrm{M}-\mathrm{HCl}$ hydrolysate of whole LPS, but not in the hydrolysates of the polysaccharide moiety, as determined by paper chromatography. Glucosamine was therefore located only in lipid A. Auto-analysis of amino compounds released by $6.1 \mathrm{M}-\mathrm{HCl}$ hydrolysis confirmed the presence of glucosamine and also showed $O$ phosphoethanolamine to be present. In addition there were small quantities of the full range of protein-derived amino acids, but diaminopimelic acid was not present.

\section{Composition of lipid $A$}

This is given in Table 2. Similar amounts of glucosamine were detected colorimetrically in hydrolysates of lipid A from all four strains. The amount of phosphate was variable. Fatty acids were liberated from LPS as their methyl esters by using methanolic $\mathrm{H}_{2} \mathrm{SO}_{4}$. GC of the transmethylation products revealed three major peaks that co-chromatographed on SP2100 $\mathrm{DOH}$ with methyl dodecanoate, methyl tetradecanoate and methyl 3-hydroxytetradecanoate. 
Table 1. Composition of LPSs from E. amylovora strains $S, T, E 8$ and P66

Assays were done as described in Methods. Amounts are expressed as $\mu$ mol (mg LPS) ${ }^{-1}$. Unless otherwise stated, all analyses were done on $2.5 \mathrm{M}-\mathrm{HCl}$ hydrolysates. The values given are representative. All determinations were done more than once; the maximum variation was $20 \%$.

\begin{tabular}{lcccc}
\multicolumn{1}{c}{ Component } & $\mathrm{S}$ & $\mathrm{T}$ & $\mathrm{E} 8$ & P66 \\
KDO & 0.14 & 0.11 & 0.36 & 0.08 \\
Heptose & 0.39 & 0.28 & 0.49 & 0.45 \\
Uronic acid & 0.53 & 0.21 & 0.43 & 0.20 \\
Glucose* & 0.46 & 0.47 & 0.69 & 0.44 \\
Galactose & 0.00 & 0.32 & 0.45 & 0.24 \\
Fucose & 0.00 & 0.38 & 0.67 & 0.08 \\
Phosphorus & 0.40 & 0.55 & 0.32 & 0.21 \\
Total amino compounds $\dagger$ & 0.75 & 2.10 & 2.60 & 1.70 \\
$\quad$ (glucosamine equivalents) & & & & \\
Total amino sugars $\dagger$ & 0.25 & 0.43 & 0.51 & 0.65 \\
$\quad$ (glucosamine equivalents) & & & & \\
Ca $^{2+}$ & 0.13 & 0.19 & 0.33 & 0.49 \\
$\mathrm{Mg}^{2+}$ & 0.17 & 0.24 & 0.06 & 0.04 \\
$\mathrm{Na}^{+}$ & 0.04 & 0.10 & 2.10 & 1.80 \\
$\mathrm{~K}^{+}$ & 0.05 & 0.01 & 0.05 & 0.03
\end{tabular}

* Assayed using glucose oxidase and by GLC of glucitol hexaacetate.

+ Determined after hydrolysis of LPS with $6 \cdot 1 \mathrm{M}-\mathrm{HCl}$.

‡ Auto-analysis of hydrolysed LPS from strain S indicated the presence of ethanolamine, $O$-phosphoethanolamine and glucosamine.

$\S$ The amino sugar was identified as glucosamine by paper chromatography of hydrolysates of LPS from strains $\mathrm{S}$ and $\mathrm{T}$.

\section{Table 2. Analysis of lipid A from LPSS of E. amylovora strains, S, T, E8 and P66}

Lipid A was derived from LPS by hydrolysis in $1 \%(\mathrm{v} / \mathrm{v})$ acetic acid for $90 \mathrm{~min}$ at $100{ }^{\circ} \mathrm{C}$, and extracted quantitatively with diethyl ether. After further hydrolysis in $6.1 \mathrm{M}-\mathrm{HCl}$ at $105^{\circ} \mathrm{C}$ for $4 \mathrm{~h}$ and removal of free fatty acid by diethyl ether extraction, samples were analysed for phosphate and glucosamine as described in Methods. Fatty acids were released from LPS by methanolysis, and analysed by GLC of the methyl ethers. Amounts are expressed as $\mu \mathrm{mol}$ (mg LPS) ${ }^{-1}$. Numbers in parentheses represent the molar ratio compared to glucosamine. The values given are representative. All determinations were done more than once; the maximum variation was $20 \%$.

\begin{tabular}{lcccc}
\multicolumn{1}{c}{ Component } & S & T & E8 & P66 \\
Phosphate & $0.07(0.28)$ & $0.09(0.39)$ & ND & $0.02(0.07)$ \\
Glucosamine* & $0.25(1.00)$ & $0.23(1.00)$ & $0.19(1.00)$ & $0.27(1.00)$ \\
$12: 0$ & $0.11(0.44)$ & $0.21(0.91)$ & $0.09(0.47)$ & $0.04(0.15)$ \\
$14: 0$ & $0.10(0.40)$ & $0.16(0.70)$ & $0.08(0.42)$ & $0.08(0.30)$ \\
3-OH 14:0 & $0.60(2.40)$ & $0.50(2.20)$ & $0.28(1.48)$ & $0.03(1.10)$ \\
Total fatty acid & $0.81(3.24)$ & $0.87(3.75)$ & $0.45(2.37)$ & $0.42(1.56)$
\end{tabular}

ND, Not determined.

* The identity of the amino sugar as glucosamine was established in hydrolysates of LPS from strains $\mathrm{S}$ and $T$ (see footnote, Table 1) and is assumed to be the same in strains E8 and P66.

Identification of fatty acid methyl esters was confirmed by comparison with authentic standards using combined GC/MS. LPS from each of the four strains contained the same fatty acids. LPS from strains P66 and E8 contained approximately 50\% less fatty acid than did the LPS of strains $\mathrm{S}$ and $\mathrm{T}$. A comparison of the molar ratio of fatty acids to glucosamine indicated approximately 3.8 and 3.2 mol fatty acid per mol of glucosamine for strains $S$ and $T$ and approximately 1.5 and $2.4 \mathrm{~mol}$ fatty acid per mol of glucosamine for strains P66 and E8.

\section{Hydrolysis of LPS under mildly acidic conditions}

Mild acid hydrolysis was used to release intact core and sidechain carbohydrates from lipid A, thus enabling investigation of the molecular structure of the LPS. Hydrolysis with $1 \%(\mathrm{v} / \mathrm{v})$ 


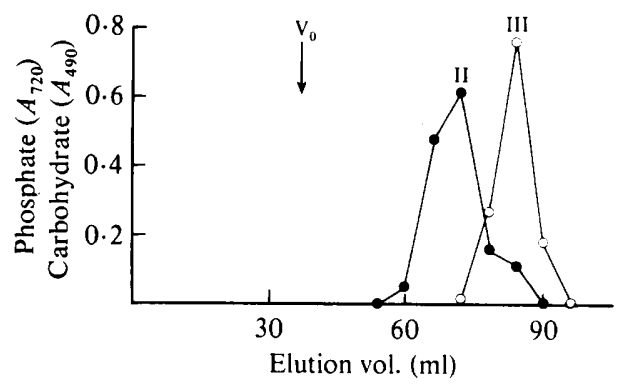

Fig. 3. Fractionation on Sephadex G-50 of carbohydrate obtained from the LPS of E. amylovora strain $\mathrm{S}$ after hydrolysis with acetic acid. LPS $(12 \mathrm{mg})$ was hydrolysed in $1 \%(\mathrm{v} / \mathrm{v})$ acetic acid for $90 \mathrm{~min}$ at $100{ }^{\circ} \mathrm{C}$. The carbohydrate was fractionated on a column $(1.5 \times 40 \mathrm{~cm})$ of Sephadex G-50 equilibrated against $50 \mathrm{~mm}$-pyridine/acetic acid buffer, pH 5.4. Fractions were assayed for total carbohydrate $(O$; $0.2 \mathrm{ml}$ portions) and for phosphate $(O ; 0.5 \mathrm{ml}$ portions). II and III refer to the peak materials later pooled. Arrow indicates void volume $\left(\mathrm{V}_{0}\right)$.

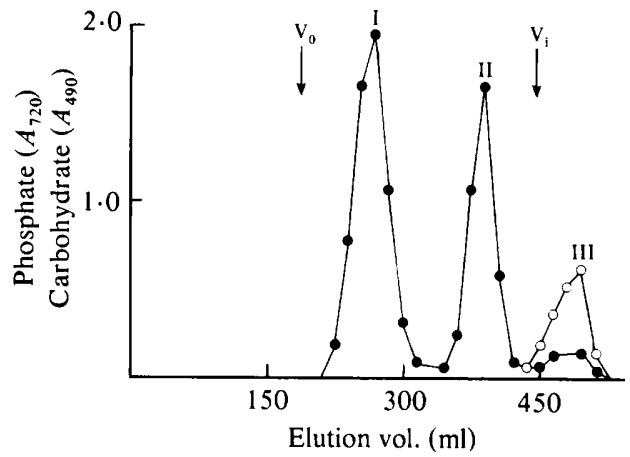

Fig. 4. Fractionation on Sephadex G-50 of carbohydrate obtained from the LPS of E. amylovora strain $T$ after hydrolysis with acetic acid. LPS $(200 \mathrm{mg})$ was hydrolysed in $1 \%(\mathrm{v} / \mathrm{v})$ acetic acid for $90 \mathrm{~min}$ at $100{ }^{\circ} \mathrm{C}$. The carbohydrate was fractionated on a column $(3.5 \times 50 \mathrm{~cm})$ of Sephadex G-50 equilibrated against $50 \mathrm{~mm}$-pyridine/acetic acid buffer, pH 5.4. Fractions were assayed for total carbohydrate (O) $0.2 \mathrm{ml}$ portions), and for phosphate $(\mathrm{O} ; 0.05 \mathrm{ml}$ portions). I, II and III refer to the peak materials later pooled. Arrows indicate void $\left(\mathrm{V}_{0}\right)$ and totally included $\left(\mathrm{V}_{\mathrm{i}}\right)$ volumes.

acetic acid for $90 \mathrm{~min}$ at $100{ }^{\circ} \mathrm{C}$ was found to give complete release of lipid A and was used routinely. After removal of insoluble material, the aqueous fraction from strain $S$ gave two peaks by gel permeation chromatography on a column of Sephadex G-50 (Fig. 3). The aqueous fraction from strain T gave three peaks (Fig. 4). Material from E8 and P66 gave similar profiles. In all cases, peaks I and II were partially included and contained carbohydrate only. Peak III, which emerged with the totally included volume, contained phosphate but little carbohydrate. Peak fractions were pooled for further analysis (Table 3).

The high $M_{\mathrm{r}}$ material of peak I from strains T, P66 and E8 contained mainly fucose, glucose and galactose with smaller amounts of uronic acid and heptose, and appeared to be core oligosaccharide substituted with a short sidechain. The two lower $M_{\mathrm{r}}$ peaks were of similar composition in all four LPSs. Peak II represented the unsubstituted core and contained heptose, glucose, uronic acid and some KDO. The low $M_{\mathrm{r}}$ peak III contained most of the KDO and the phosphate and amino compounds including $O$-phosphoethanolamine, released during the hydrolysis of the core-lipid A region. LPS from strains T, P66 and E8 was therefore shown to contain short sidechains consisting of glucose, galactose and fucose. LPS of strain S consisted of lipid A substituted with core only and was therefore rough. 
Table 3. Composition of the carbohydrate fractions (I, II and III) derived from LPSs of E. amylovora strains $S, T, E 8$ and P66 by hydrolysis with acetic acid and chromatography on Sephadex $G-50$

Peaks I, II and III (see Figs 3 and 4) were analysed as described in Methods. Total amino sugars and total amino compounds were estimated after further hydrolysis of the material in $2.5 \mathrm{M}-\mathrm{HCl}$ or $0.5 \mathrm{M}$ $\mathrm{H}_{2} \mathrm{SO}_{4}$, and $6.1 \mathrm{M}-\mathrm{HCl}$ respectively. Sidechain samples were hydrolysed using $0.5 \mathrm{M}-\mathrm{H}_{2} \mathrm{SO}_{4}$, and fucose, galactose and glucose were estimated by GLC of their corresponding alditol acetates. Core samples were hydrolysed with $2.5 \mathrm{M}-\mathrm{HCl}$ (for strains $\mathrm{S}$ and $\mathrm{T}$ ) or $0.5 \mathrm{M}-\mathrm{H}_{2} \mathrm{SO}_{4}$ (for strains E8 and P66). Amounts are expressed as $\mu \mathrm{mol}$ (mg LPS $)^{-1}$. The values given are representative. All determinations were done more than once; the maximum variation was $20 \%$.

\begin{tabular}{|c|c|c|c|c|c|c|c|c|c|c|c|}
\hline \multirow[b]{2}{*}{ Component } & \multicolumn{2}{|c|}{$\mathbf{S}$} & \multicolumn{3}{|c|}{$\mathrm{T}$} & \multicolumn{3}{|c|}{ E8 } & \multicolumn{3}{|c|}{ P66 } \\
\hline & II & III & I & II & III & I & II & III & I & II & III \\
\hline Fucose & 0.00 & & 0.17 & $\operatorname{tr}$ & & 0.43 & 0.08 & & $0 \cdot 22$ & 0.02 & \\
\hline Galactose & 0.00 & & 0.23 & tr & & 0.39 & 0.05 & & 0.23 & 0.03 & \\
\hline Glucose & $0 \cdot 22$ & & 0.24 & $0 \cdot 17^{*}$ & & 0.51 & $0 \cdot 21$ & & $0 \cdot 31$ & $0 \cdot 21$ & \\
\hline Uronic acid & $0 \cdot 21$ & & 0.04 & 0.27 & & 0.05 & $0 \cdot 12$ & & 0.02 & 0.08 & \\
\hline Heptose & $0 \cdot 26$ & & 0.08 & $0 \cdot 16$ & & 0.09 & $0 \cdot 15$ & & 0.06 & $0 \cdot 11$ & \\
\hline KDO & 0.02 & 0.04 & 0.00 & 0.02 & 0.03 & tr & tr & 0.05 & $\operatorname{tr}$ & $\operatorname{tr}$ & 0.01 \\
\hline $\begin{array}{l}\text { Total amino compounds } \\
\text { (glucosamine } \\
\text { equivalents) }\end{array}$ & 0.00 & $0 \cdot 19$ & 0.24 & 0.31 & $\operatorname{tr}$ & $\operatorname{tr}$ & tr & 0.00 & $0 \cdot 21$ & $0 \cdot 11$ & 0.00 \\
\hline $\begin{array}{l}\text { Total amino sugars } \\
\text { (glucosamine } \\
\text { equivalents) }\end{array}$ & 0.00 & 0.00 & 0.00 & 0.04 & 0.00 & 0.00 & $0 \cdot 13$ & 0.00 & 0.08 & 0.00 & 0.00 \\
\hline Phosphorus & 0.00 & $0 \cdot 20$ & 0.00 & 0.00 & 0.06 & 0.00 & $0 \cdot 00$ & 0.06 & $0 \cdot 00$ & 0.00 & 0.02 \\
\hline
\end{tabular}

\section{DISCUSSION}

During this investigation it was found that either the PW or PCP extraction methods would extract LPS when used alone and that sequential extraction by the two techniques also yielded LPS. Sequential extraction was used routinely. Samples of LPS extracted using PCP and PW contained identical neutral sugars and fatty acids. Similarly, mild acid hydrolysis of PCP- and PW-extracted LPS yielded core-sidechain and unsubstituted core oligosaccharides of similar sizes. It was concluded that the ability to extract LPS by the two techniques did not reflect the presence of two different LPS populations. The substitution of the core with short sidechains, composed in part of a 6-deoxysugar, might plausibly confer on the LPS molecule partial lipid (PCP) solubility as well as solubility in a more polar phase (PW). The recovery of LPS by sequential extraction may reflect a relatively inefficient initial extraction by the PCP method: of the four lipopolysaccharides examined, only LPS of strain S was quantitatively extracted into PCP and behaved as a typical rough species.

The appearance of LPS in culture supernatants has been reported for several strains of Escherichia coli and Salmonella (Knox et al., 1967; Marsh \& Crutchley, 1967), and Brade \& Galanos (1982) showed that a strain of Acinetobacter shed as much as $40 \%$ of its LPS into the culture medium. Analysis of culture supernatant LPS of E. amylovora showed that it had the same composition and structure as the LPS extracted from cells. It is not clear at this stage whether the LPS is lost from the outer membrane because of the bulk culture methods used in this study, or whether the E. amylovora normally releases LPS regardless of growth conditions. However, the loss of LPS from the outer membrane may support the hypothesis of Chatterjee $e t$ al. (1977), that the outer membrane of E. amylovora is defective in a way that allows leakage of periplasmic enzymes.

From the results of deacylation and disaggregation experiments it was concluded that the LPS preparations were free from contaminating polysaccharides. It would appear that the cultural 
procedure used effectively suppressed the production of capsule/EPS by $E$. amylovora.

During the disaggregation experiments using TEB, the exchange of counter-ion was shown to be a slow process, suggesting that at the concentrations used LPS competes strongly with EDTA for the divalent cation present.

The residue analysis revealed similarities with enterobacterial LPS. The core contained KDO, heptose and glucose, but was unusual in that it also contained uronic acid. Lipid A contained fatty acids common to enterobacterial LPS (Wilkinson, 1977), including 3-OH 14:0. The sidechains of the LPS contained the three common neutral sugars fucose, galactose and glucose, but were relatively short. The structure of the LPS from E. amylovora is recognizably similar to that of other members of the Enterobacteriaceae and the findings presented here therefore support the present classification of the organism within this family. The LPS also shows two similarities to LPS of Rhizobium: both contain uronic acid in the core, and both have short sidechains (Carlson, 1982).

Little information on the LPS from E. amylovora has been previously published. Chatterjee $e t$ al. (1977) stated that the LPS contained KDO, heptose, glucose, galactose, glucosamine and rhamnose, and was smooth. Romeiro et al. (1981 b) extracted LPS from strain E8 using a modified PW method. Mild acid hydrolysis of the LPS was attempted using $0.09 \%$ acetic acid at $100{ }^{\circ} \mathrm{C}$ for $90 \mathrm{~min}$, an unusual and very mild treatment. Gel filtration of the resulting hydrolysate on Bio-Gel P30 produced a confusing profile consisting of two carbohydrate peaks: the first eluted at the void volume and contained phosphate; the second was partially included and contained KDO. Significantly, no separate totally-included KDO peak was detected, as would have been expected if the lipid A-KDO linkage had been hydrolysed. We would suggest that the excluded carbohydrate peak may have represented contaminating polysaccharide, and that the second peak may have consisted of LPS which had not been hydrolysed completely under the conditions used. The conclusion of Romeiro et al. $(1981 b)$ that the LPS has long sidechains was therefore erroneous and at odds with the findings presented here.

Bradshaw-Rouse et al. $(1981,1982)$ reported on the sugar composition of LPS from Erwinia chrysanthemi and Erwinia stewartii. There is possibly some similarity between LPS from $E$. stewartii and E. amylovora. Although mild acid hydrolysis was not used, SDS-PAGE of the LPS revealed that LPS from only two of nine strains contained the slow moving bands indicative of smooth LPS. The majority of the LPSs were therefore classified as rough. A recent report by De Boer et al. (1985) on the composition of LPS from Erwinia carotovora also indicated similarities in sugar composition between LPS of this organism and that of E. amylovora. The LPS of some strains required extraction with PCP, which may indicate that the molecule is rough or bears short sidechains.

From the four strains investigated, there would appear to be little difference in residue composition between LPS of the virulent E. amylovora isolate $\mathrm{T}$ and those of the avirulent isolates E8 and P66, but a more detailed structural comparison may reveal more subtle differences. A clear difference between LPS of strain T and that of its phage-resistant mutant $S$ was the absence of sidechains from the mutant LPS.

It is now known that LPS and EPS from E. amylovora share certain residues, namely glucose, galactose and uronic acid. Billing (1984) showed that strain S would revert to EPS production when grown on media supplemented with galactose, and concluded that blockage of capsule/EPS formation was due to a lack of UDP-glucose-4-epimerase. In the present study, we have shown that galactose is also a component of the LPS sidechain. The failure of strain $S$ to elaborate a sidechain can therefore also be accounted for by the absence of the epimerase. In this particular mutant blockage of EPS production has led simultaneously to the production of rough LPS.

The determination of the structure of the sidechain from strain $T$ is planned to be the subject of a further publication.

T.C.R. was supported by an SERC-CASE studentship. We thank $\mathrm{Mr} \mathrm{T}$. Samuelson for metal ion determinations and Dr E. Billing for helpful discussion. 


\section{REFERENCES}

Albersheim, P., Nevins, D. J., English, P. D. \& KARR, A. (1967). A method for the analysis of sugars in plant cell-wall polysaccharides by gas-liquid chromatography. Carbohydrate Research 5, 340-345.

Ayers, A. R., Ayers, S. B. \& GoOdman, R. N. (1979). Extracellular polysaccharide of Erwinia amylovora: a correlation with virulence. Applied and Environmental Microbiology 38, 659-666.

Bauchop, T. \& ElSDEN, S. R. (1960). The growth of microorganisms in relation to their energy supply. Journal of General Microbiology 23, 457-469.

Beer, S. V., SJulin, T. M. \& Aldwinckle, H. S. (1983). Amylovorin-induced shoot wilting: lack of correlation with susceptibility to Erwinia amylovora. Phytopathology 73, 1328-1333.

BENNETT, R. A. (1980). Evidence for the two virulence determinants in the fireblight pathogen Erwinia amylovora. Journal of General Microbiology 116, 351356.

Bennett, R. A. \& Billing, E. (1980). Origin of the polysaccharide component of ooze from plants infected with Erwinia amylovora. Journal of General Microbiology 116, 341-349.

BILliNG, E. (1984). Studies on avirulent strains of Erwinia amylovora. Acta horticulturae 151, 249-253.

BlumenkrantZ, N. \& Asboe-Hansen, G. (1973). New methods for the quantitative determination of uronic acids. Analytical Biochemistry 54, 484-487.

BraDe, H. \& Galanos, C. (1982). Isolation, purification and chemical analysis of the lipopolysaccharide and lipid A of Acinetobacter calcoaceticus NCTC 10305. European Journal of Biochemistry 122, 233-237.

Bradshaw-Rouse, J. J., Whatley, M. H., Coplin, D. L., Woods, A., Sequeira, L. \& Kelman, A. (1981). Agglutination of Erwinia stewartii strains with a corn agglutinin: correlation with extracellular polysaccharide production and pathogenicity. Applied and Environmental Microbiology 42, 344-350.

Bradshaw-Rouse, J. J., Sequeira, L. \& Kelman, A. (1982). Sugar composition of the lipopolysaccharide (LPS) of Erwinia chrysanthemi. Phytopathology 72, 1134.

Carlson, R. W. (1982). Surface chemistry. In Nitrogen Fixation, vol. 2, Rhizobium, pp. 199-234. Edited by J. W. Broughton. Oxford: Clarendon.

Carlson, R. W., Sanders, R. E., Napoli, C. \& AlbERSheIM, P. (1978). Host-symbiont interactions. III: Purification and partial characterization of Rhizobium lipopolysaccharides. Plant Physiology 62, 912-917.

Chatterjee, A. K., Buss, R. F. \& Stark, M. P. (1977). Unusual susceptibility of Erwinia amylovora to antibacterial agents in relation to the barrier function of its cell envelope. Antimicrobial Agents and Chemotherapy 11, 897-905.

Chester, I. R. \& MEADOW, P. M. (1975). Heterogeneity of the lipopolysaccharide from Pseudomonas aeruginosa. European Journal of Biochemistry 58, 273282.

De Boer, S. H., Bradshaw-Rouse, J. J., Sequeira, L.
\& MCNaughton, M. E. (1985). Sugar composition and serological specificity of Erwinia carotovora lipopolysaccharides. Canadian Journal of Microbiology 31, 583-586.

Galanos, C., Lüderitz, O. \& WestPhal, O. (1969). A new method for the extraction of R-lipopolysaccharides. European Journal of Biochemistry 9, 245-249.

Goodman, R. N. (1983). Fireblight - a case study. In Biochemical Plant Pathology, pp. 45-63. Edited by J. A. Callow. Chichester: John Wiley.

Goodman, R. N., Huang, J. S. \& Huang, P. Y. (1974). Host specific phytotoxic polysaccharides from apple tissue infected with Erwinia amylovora. Science 184, 1081-1082.

Knox, K. W., Cullen, J. \& Work, E. (1967). An extracellular lipopolysaccharide-phospholipid-protein complex produced by Escherichia coli grown under lysine-limiting conditions. Biochemical Journal 103, 192-201.

LÜDERITZ, O., RisSe, H. J., SChulte-Holthausen, H., Strominger, J. L., Sutherland, I. W. \& WestPHAL, O. (1965). Biochemical studies of the smoothrough mutation in Salmonella minnesota. Journal of Bacteriology 89, 343-345.

Marsh, D. G. \& Crutchley, M. J. (1967). Purification and physico-chemical analysis of fractions from the culture supernatant of Escherichia coli $078 \mathrm{~K} 80$ : free endotoxin and a non-toxic fraction. Journal of General Microbiology 47, 405-420.

Quirk, A. V., Sletten, A. \& HignetT, R. C. (1976). Properties of phage-receptor lipopolysaccharide from Pseudomonas morsprunorum. Journal of General Microbiology 96, 375-381.

Romeiro, R., KARR. A. L. \& GoOdman, R. N. (1981 $a$ ). Isolation of a factor from apple that agglutinates Erwinia amylovora. Plant Physiology 68, 772-777.

Romeiro, R. D., KarR, A. L. \& GoOdman, R. N. $(1981 b)$. Erwinia amylovora cell wall receptor for apple agglutinin. Physiological Plant Pathology 19, 383-390.

Slade, M. B. \& Tiffin, A. I. (1978). Serological crossreactions between Erwinia amylovora and Erwinia herbicola. Proceedings of the 4th International Conference on Plant Pathogenic Bacteria (Angers, 1978), pp. 289-293. Angers, France: ISPP/INRA.

Smith, A. R. W., Zamze, S. E. \& Hignett, R. C. (1985). Composition of lipopolysaccharide from Pseudomonas syringae pv. morsprunorum and its digestion by bacteriophage A7. Journal of General Microbiology 131, 963-974.

Van-Alfen, N. K. \& McMillan, B. D. (1982). Macromolecular plant wilting toxins: artifacts of the bioassay method? Phytopathology 72, 132-135.

WestPHal, O. \& JANN, K. (1965). Bacterial lipopolysaccharides: extraction with phenol-water and further applications of the procedure. Methods in Carbohydrate Chemistry 5, 83-91.

Wilkinson, S. G. (1977). Composition and structure of bacterial lipopolysaccharides. In Surface Carbohydrates of the Prokaryotic Cell, pp. 97-175. Edited by I. W. Sutherland. London: Academic Press. 